\title{
Socio-economic impact of mobile phones
}

\author{
${ }^{1}$ Dr Hemlata Borkar, ${ }^{2}$ Shashibala Borkar \\ ${ }^{1}$ Senior Assistant Professor, SOS in Sociology, Pt RSU, Raipur, C. G. \\ ${ }^{2}$ PhD Scholar, SOS in History, Pt RSU, Raipur, C. G.
}

\begin{abstract}
In this paper the authors will try to identify, and measure where possible, social and economic impacts attributable to increase in the number of mobile phone subscribers.

While different aspects of growth e.g. GDP and mobile penetration for a country can be correlated; measuring exact contribution of it, is not the scope of this work.

Apart from economic aspects the sociological changes being brought about by increased use of mobile is also going to be discussed. A more qualitative analysis is done in this regard due to difficulty in obtaining primary or secondary data.

The paper concludes with the observation that invent of mobile telephony has had significant impact on social and economic aspects of society.
\end{abstract}

Keywords: Mobile phones, socio-economic effects of mobile phones

\section{Introduction:}

Importance of mobile phones is felt every day by us. The primary objective of a mobile device is to have us connected to the world and facilitate flow of information from us to it and vice versa. In case of India, mobile phones are also basic telephonic device used much more than fixed lines due to cost advantages.

From point of view of economics, mobile phones reduce information asymmetry hence bringing more transparency in the system. They also bring efficiency into the system by making most recent information quickly available to user. Mobile banking is one direct consequence of mobile devices.

Mobile phones also have great sociological implications directly impacting our lives.

How big is mobile subscriber base in India?

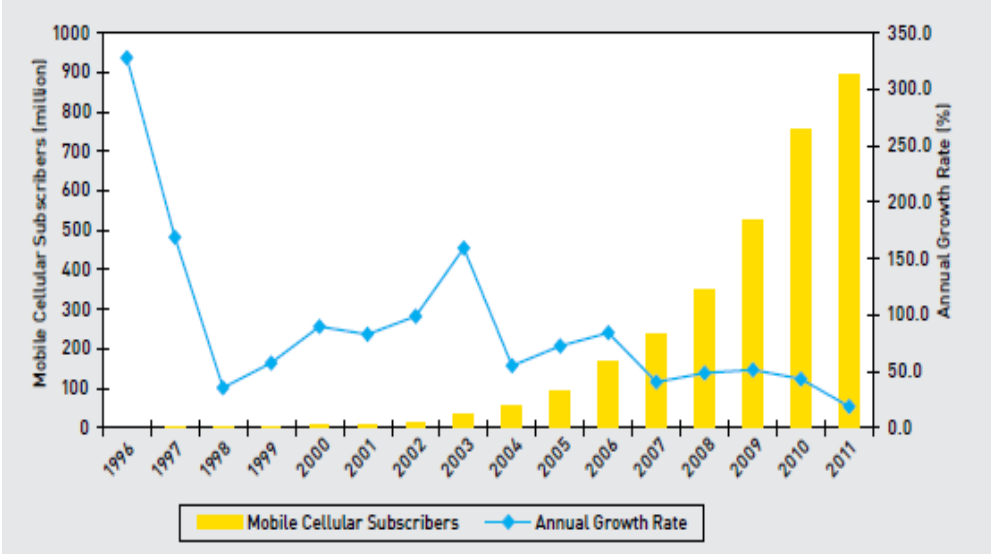

Figure 1: Growth of mobile subscribers in India from 1996

Source: Telecom Regulatory Authority of India (TRAI)

As can be seen from the figure above since beginning of $21^{\text {st }}$ century, mobile phone penetration has shown significant increase. With over 900 million subscribers, we have more than 75 subscribers for every 100 people; although there is significant difference between urban (169 subscribers per 100 people) and rural (38 subscribers per 100 people) population.

With such penetration, a better understanding of its impact is required to make fullest use of its advantages or minimizing disadvantages, if any.

\section{Economic impact of mobile phones:}

In this section, we would explore different cases where it is shown that higher mobile penetration and economic growth are positively interrelated. 
a) In the figure below, we see that states with more mobile penetration is very strongly correlated with GSDP of states. Roller and Waverman in their paper established that $10 \%$ increase in the penetration result in $2.8 \%$ increase in the GDP.

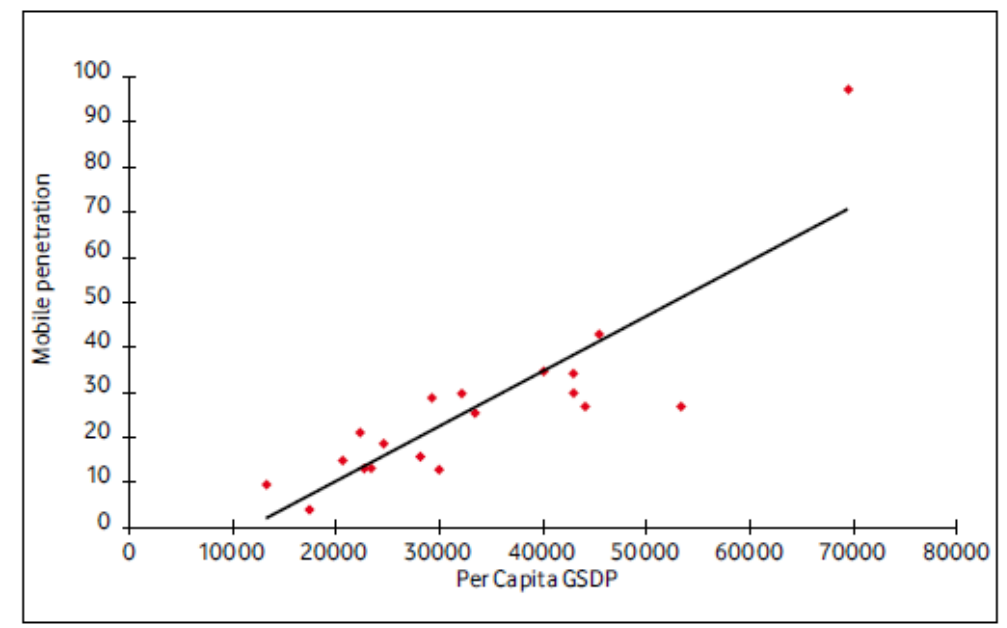

Figure 2: Mobile penetration and Per Capita GSDP for Indian States

Source: TRAI

b) Jensen (2007) conducted a research into use of mobile phones by fishermen in Kerala to increase efficiency and make more profit in their profession. Mobile phones were used by fishermen to be quickly knowledgeable of market conditions such as demand and prices of their product and it helped them increase their profit by $8 \%$ and reduce waste of around $8 \%$ of their daily produce.

\section{Sociological impact of mobile phones:}

a) Effective disaster management: Mobile phones can be used to effectively tackle emergency situation to individuals as well as to larger population.

Deloitte (2008) offered a specific example. In 2007, during severe flooding in Indonesia, DiGi was able to identify all its subscribers in Malaysia that were registered as being immigrants from Indonesia and offered them free airtime.

b) Mobile phones are associated with improved economic status for the poor: In a survey, conducted by Sarin and Jain (2009), it was found that $48 \%$ of respondents believed that their economic status has improved once they had access to a mobile phone

c) In her research, Dr Plant tries to defined personalities based on their behavior on mobile phone - swift talker, solitary owl, chattering sparrow, noisy starling, calm dove and flashy peacock. She also points out the inclusion of language used in SMS into mainstream language.

\section{Conclusion:}

Mobile phones are reality of present day. They impact all aspect of our lives. In this paper, we saw few examples of how socio-economic development is affected by it.

\section{References:}

[1]. Roller, Lars-Hendrik and Waverman, Leonard (2001); Telecommunications Infrastructure and Economic Development: A Simultaneous Approach; The American Economic Review, Volume 91, 4th Issue, Pg; 909-923.

[2]. Telecom Sector in India: A Decadal Profile; TRAI

[3]. Jensen, Robert. August 2007. The Digital Provide: Information Technology, Market Performance and Welfare in the South Indian Fisheries Sector. The Quarterly Journal of Economics. Volume CXXII, Issue 3. pages 879 to 924

[4]. Deloitte \& Touche LLP, 2007, Economic Impact of Mobile in Bangladesh, Malaysia, Pakistan, Serbia, Thailand \& Ukraine.

[5]. Dr Sadie Plant, The effects of mobile telephones on social and individual life 